\title{
Something wicked this way comes: What health care providers need to know about Candida auris
}

\author{
IS Schwartz ${ }^{1 *}$, SW Smith ${ }^{1}$, TC Dingle D $^{2,3}$
}

\begin{abstract}
Candida auris is a fungal pathogen that recently emerged and rapidly spread around the globe. It is now in Canada. C. auris can cause invasive disease with high mortality rates, is frequently resistant to one or more classes of antifungals, and can be difficult to identify in some clinical microbiology laboratories. C. auris can also involve prolonged colonization of patients' skin and contamination of surrounding environments, resulting in nosocomial outbreaks in hospitals and long-term care facilities.
\end{abstract}

Clinicians, infection prevention and control practitioners and public health officials should be aware of how to mitigate the threat posed by this pathogen. Index cases of $C$. auris should be suspected in patients with invasive candidiasis and recent hospitalization in global regions where $C$. auris is prevalent, as well as in patients who fail to respond to empiric antifungal therapy and from whom unidentified or unusual Candida species have been isolated. If a case of $C$. auris infection or colonization is identified or suspected, the following should take place: notification of local public health authorities and infection prevention and control practitioners; placement of colonized or infected patients in single rooms with routine contact precautions; daily and terminal environmental disinfection with a sporicidal agent; contact tracing and screening for $C$. auris transmission; and referral of suspicious or confirmed isolates to provincial laboratories. Patients with symptomatic disease should be treated with an echinocandin pending the results of antifungal susceptibility testing, preferably in consultation with an infectious disease specialist. Through the vigilance of front-line health care workers and microbiologists, robust infection prevention and control practices, and local and national surveillance efforts, C. auris can be detected quickly, infections managed and transmissions prevented to protect patients in our health care system.

\author{
Affiliations \\ ${ }^{1}$ Division of Infectious Diseases, \\ Department of Medicine, \\ University of Alberta, \\ Edmonton, $A B$ \\ ${ }^{2}$ Division of Diagnostic \\ and Applied Microbiology, \\ Department of Laboratory \\ Medicine and Pathology, \\ University of Alberta, \\ Edmonton, $\mathrm{AB}$ \\ ${ }^{3}$ Provincial Laboratory for Public \\ Health, Edmonton, AB
}

${ }^{\star}$ Correspondence:

ilan@ualberta.ca

Suggested citation: Schwartz IS, Smith SW, Dingle TC. Something wicked this way comes: What health care providers need to know about Candida auris. Can Commun Dis Rep 2018;44(11):271-6. https://doi. org/10.14745/ccdr.v44i11a01

Keywords: Candida auris, candidemia, fungal infections, mycology, antifungal resistance, multidrug resistance, diagnosis, nosocomial, infection prevention and control

\section{Introduction}

In July 2017, the first known case of multidrug-resistant Candida auris was reported in Canada in an individual who had a two-year history of recurrent ear complaints after returning from a trip to India that was marred by hospitalization for a brain abscess following oral surgery (1). This marked the arrival in Canada of a pathogen that has recently been spreading across the globe. The ability of this fungus to cause invasive disease, its frequent resistance to one or more classes of antifungal agents and its demonstrated potential for nosocomial transmission is of concern to clinicians and public health professionals alike $(2,3)$.
The objective of this article is to summarize what we know about this fungus; outline the challenges of diagnosis, treatment and infection prevention and control, and identify what is being done to track and contain the spread of this pathogen in Canada.

\section{Where in the world is $C$. auris?}

C. auris was first described in Japan in 2009; since then,

C. auris infections have been reported in at least 30 countries 
on six continents (4). Whole-genome sequence analyses of global isolates have demonstrated that these cluster into closely related (clonal) geographic clades (5) suggesting the near-simultaneous emergence of $C$. auris on at least three continents. For example, the average genetic distances between the East Asian, South Asian, South African and South American clades were 40,000 to 140,000 single nucleotide polymorphisms (SNPs), whereas on average, fewer than 70 SNPs separated any two isolates within a given clade (3). The reasons for this phenomenon are unknown.

In some countries, C. auris has already led to a significant burden of hospital-acquired disease. For example, C. auris is the cause of candidemia in $10 \%$ of cases nationally in South Africa (6), and $38 \%$ of cases in one referral hospital in Kenya (Okinda $\mathrm{N}$ et al. Candidemia at a referral hospital in sub-Saharan Africa: emergence of Candida auris as a major pathogen. Poster presented at: European Congress of Clinical Microbiology and Infectious Diseases; 2014 May 10-13; Barcelona, Spain). In India, C. auris was implicated in $5 \%$ of candidemia cases in 27 intensive care units (ICUs), although some Indian centres report proportions of $17.5 \%-30 \%(7,8)$. As of July 31,2018 , the Centers for Disease Control and Prevention (CDC) in the United States (US) reported 361 confirmed clinical cases of $C$. auris in US health care settings; an additional 699 colonized patients were diagnosed in four states with active surveillance (4). In Europe, at least 120 cases of candidemia and 466 cases of colonization occurred from 2013 to 2017 (9).

In Canada, the first two patients reported to be infected with C. auris had received health care in India $(1,10)$. In one case, genomic characterization suggested that the infection was imported from the Indian subcontinent (11). Additional imported cases are anticipated. Transmission in Canadian health care facilities is inevitable.

\section{What are clinical features of disease caused by $C$. auris?}

The clinical spectrum of $C$. auris infection ranges from asymptomatic colonization to invasive candidiasis, most commonly in the form of healthcare-associated candidemia (12). Bloodstream infections can be protracted and difficult to treat, and crude mortality rates of approximately 30\%-60\% have been reported $(5,13,14)$. Metastatic complications, such as spondylodiscitis, endocarditis and ventriculitis, have been described (13). Other frequently reported clinical syndromes include otomycosis and otomastoiditis $(15,16)$ : in fact, the etymology of the fungus reflects the anatomic origin of the first identified isolate, which was collected from a patient's ear (17). Involvement of other sites, including respiratory, urogenital, abdominal, and skin and soft tissue, has also been reported (18).

\section{Who becomes infected by $C$. auris and how?}

Patients who develop candidemia caused by $C$. auris usually have risk factors in common with patients with disease caused by other Candida species $(6,13,14,19)$. These include hospitalization and, in particular, admission to an ICU, use of central venous catheters, abdominal surgery and exposure to broad-spectrum antibiotics or antifungals (20).

There are several ways in which the pathogenesis of $C$. auris appears to differ from classically encountered Candida species (Table 1) (21). With the exception of C. parapsilosis, a skin colonizer, the majority of clinically important non-auris Candida species are commensals of the human gastrointestinal tract (21). The pathogenesis of candidemia caused by these species typically involves gut translocation of yeasts $(21,22)$; although nosocomial transmission of Candida is occasionally reported, disease is most commonly caused by strains that are part of the patient's endogenous flora (23).

Table 1: Differences between Candida auris and classical pathogenic Candida species

\begin{tabular}{|c|c|c|}
\hline Feature & Candida auris & $\begin{array}{c}\text { Classical Candida } \\
\text { species }^{a}\end{array}$ \\
\hline Habitat & Commensal of the skin & $\begin{array}{l}\text { Commensals of the } \\
\text { gastrointestinal tract }\end{array}$ \\
\hline $\begin{array}{l}\text { Pathogenesis of } \\
\text { infection }\end{array}$ & Exogenous & Endogenous \\
\hline $\begin{array}{l}\text { Healthcare-associated } \\
\text { infections }\end{array}$ & Common & Uncommon \\
\hline $\begin{array}{l}\text { Environmental } \\
\text { contamination }\end{array}$ & Common & Uncommon \\
\hline Multidrug resistance & Common & Uncommon \\
\hline
\end{tabular}

C. auris is primarily carried on the skin of colonized patients, and this can lead to contamination of the patient's environment and spread to health care workers and other patients. Moreover, C. auris isolates implicated in healthcare-associated outbreaks have been clonally related, suggesting disease is caused by exogenous strains that are nosocomially spread $(5,13,24,25)$.

\section{What are the diagnostic challenges?}

C. auris can be difficult to detect by routine laboratory testing. This may lead to delays in identifying and isolating colonized or infected patients. Commercial biochemical identification systems commonly used in clinical microbiology laboratories are unreliable for $C$. auris identification (26). For example, C. auris can be misidentified by VITEK-2 (bioMérieux, Marcy-l'Étoile, 
France) (typically as C. haemulonii) (26) and by API20CAUX (usually as Rhodotorula glutinis, C. sake or Saccharomyces cerevisiae) (27). This may change as biochemical identification system databases are updated; for example, VITEK-2 YST card v. 8.01 now includes $C$. auris.

C. auris can be identified accurately using matrix-assisted laser desorption ionization time-of-flight (MALDI-TOF) mass spectrometry instruments with databases that include $C$. auris (these include the most recent Bruker MALDI Biotyper CA and Research Use Only [RUO] databases, and the bioMérieux VITEK MS RUO database [v4.14 with Saccharomycetales package]) and by molecular-based sequencing methods.

\section{What are the treatment challenges?}

In general, C. auris isolates are less susceptible to antifungals than other Candida species, although patterns of susceptibility appear to be related to the geographic clade. Resistance to fluconazole is widespread, albeit not universal as was initially feared (2), and fluconazole resistance is now thought to be an acquired rather than a shared trait (21). Rates of fluconazole resistance have ranged from $14 \%$ among isolates from Colombia (25) to $>90 \%$ among isolates belonging to the South Asian clade $(14,28)$. Resistance to amphotericin B and the echinocandins also appear to be heterogeneous. Several studies have found amphotericin B resistance rates around $30 \%(5,14,25)$; alternatively, Chowdhary et al. reported amphotericin $B$ resistance in 27/350 (8\%) of Indian isolates (28). Significant variation in rates of amphotericin $B$ resistance were encountered between regions in Columbia (25). Echinocandin resistance occurs in approximately $2 \%-5 \%$ of isolates $(5,28,29)$. Resistance to two antifungal classes occurred in $41 \%$ of global isolates tested (5). In rare cases, isolates can be resistant to all three major classes of antifungal agents (5).

\section{What are the challenges in infection prevention and control?}

Nosocomial outbreaks are anticipated because patients can remain colonized and/or their environments can remain contaminated for weeks to months after infection $(14,24,25,30)$. Large-scale hospital outbreaks in the United Kingdom (UK) have been associated with multi-use axillary thermometers (31); and in Spain with the use of blood-pressure cuffs (31). Moreover, $C$. auris has been recovered from a wide range of fomites from patient environments $(13,14,24,25)$. Surface cationic-active disinfectants and quaternary ammonium disinfectants are ineffective against $C$. auris $(13,33,34)$. C. auris is also relatively resistant to killing by ultraviolet light (35). Chlorhexidine gluconate, iodinated povidone, chlorine bleach and $\mathrm{H}_{2} \mathrm{O}_{2}$ vapour appear to be effective against $C$. auris (36).
The role of health care workers in spreading C. auris is still unknown. During investigation of the outbreak in the UK, C. auris was isolated from the nares of 1/258 health care workers, a nurse who was providing care for a patient who was heavily colonized (24). Moreover, an outbreak investigation in Colombia isolated C. auris from the hands of two health care workers and the groin of one out of six health care workers. Whole-genome sequencing established that these were genetically identical to strains isolated from a patient and his or her environment (25).

Tracking and containing $C$. auris can be particularly challenging due to interfacility transfer of infected or colonized patients in whom this status may not yet be recognized, potentiating spread of $C$. auris between facilities (14). For example, in New York, 112 patients in hospitals and long-term care facilities were affected: 61 had candidemia and 51 additional patients were found to be colonized on screening. Infected or colonized patients were transferred between a total of 24 hospitals and 24 long-term care facilities in the 90 days before their infection or colonization status was recognized (14).

\section{Implications for clinical care}

The prompt identification, management and containment of patients infected or colonized with $C$. auris require collaboration by hospitalists/intensivists, microbiologists, infectious disease experts, and infection control and prevention practitioners.

Clinicians should be aware of the yeast identification methods used by their local microbiology laboratory and consider C. auris when unidentified or unusual Candida species are isolated from patients who fail to respond to empiric antifungal therapy (37). Consultation with a microbiologist is recommended when C. auris is suspected. Isolates that are suspicious for or confirmed as $C$. auris should be referred to provincial laboratories for further testing. Given the challenges in predicting antifungal susceptibility patterns, antifungal susceptibility testing is recommended for all clinical C. auris isolates. Treatment of disease should be guided by antifungal susceptibility testing results, although echinocandins are appropriate for empiric therapy pending these results. Early consultation with an infectious disease expert is advised. Treatment of asymptomatic colonization is not recommended.

The identification of patients in whom infection or colonization with C. auris is suspected or confirmed should prompt consultation with local infection prevention and control practitioners. Infected or colonized patients should be isolated in private rooms; routine practices and contact precautions should be taken; and rooms should be cleaned daily with sporicidal disinfectants. Whether and when to discontinue isolation precautions is still being debated. The CDC currently recommends that infected or colonized patients be tested periodically with composite groin and axillary swabs for fungal culture to test for persistent colonization, with the proviso that 
patients can be de-isolated after two consecutive screening swabs (38). In practice, few reported patients have met such criteria (14). Alternatively, Public Health England recommends that isolation precautions be continued for the duration of a patient's admission to hospital (39). This recommendation is in part because patients can become re-colonized after testing negative (Silke Schelenz, "Management of Candida auris outbreaks at a national level". 20 $0^{\text {th }}$ Congress of the International Society for Human and Animal Mycology, Amsterdam, The Netherlands July 2018).

Table 2 shows a summary of how to detect, assess and manage C. auris. Further infection prevention and control guidelines are available from the CDC (39).

\section{Table 2: What to do to detect and manage Candida auris}

\begin{tabular}{|l|l|}
\hline \multicolumn{1}{|c|}{ What to do } & \multicolumn{1}{c|}{ How } \\
\hline $\begin{array}{l}\text { Keep a high index of } \\
\text { suspicion }\end{array}$ & $\begin{array}{l}\text { Consider C. auris in patients who: } \\
\text { received health care in countries (or US states) } \\
\text { where C. auris is prevalent, as tracked by the } \\
\text { CDC (4) } \\
\text { have a clinical syndrome consistent with } \\
\text { candidiasis and fail to respond to empiric } \\
\text { antifungal therapy and from whom an atypical } \\
\text { or unidentified yeast is isolated }\end{array}$ \\
\hline $\begin{array}{l}\text { Assess for C. auris } \\
\text { specifically }\end{array}$ & $\begin{array}{l}\text { Consult with a microbiologist and/or infectious } \\
\text { disease specialist } \\
\text { Refer suspicious or confirmed isolates to relevant } \\
\text { provincial laboratory for further testing or for } \\
\text { referral to the National Microbiology Laboratory }\end{array}$ \\
\hline $\begin{array}{l}\text { Manage C. auris with a } \\
\text { robust clinical infection } \\
\text { control and public } \\
\text { health response }\end{array}$ & $\begin{array}{l}\text { Notify the institutional infection prevention and } \\
\text { control team } \\
\text { Notify local public health officials, who will notify } \\
\text { their provincial/territorial counterparts (who will } \\
\text { notify the Public Health Agency of Canada) } \\
\text { Place patient in single room with contact } \\
\text { precautions in addition to routine practices } \\
\text { In case of symptomatic disease, begin treatment, } \\
\text { preferably with guidance from an infectious } \\
\text { disease specialist treatment of asymptomatic } \\
\text { colonization is not recommended) } \\
\text { Order daily and terminal cleaning of the patient's } \\
\text { environment with sporicidal disinfectant } \\
\text { Enable local public health officials to initiate } \\
\text { contact tracing and screening to assess for C. auris } \\
\text { transmission } \\
\text { Order composite swab of axilla and groin when } \\
\text { indicated for patient screening }\end{array}$ \\
\hline
\end{tabular}

Abbreviations: C. auris, Candida auris; CDC, Centers for Disease Control and Prevention; US, United States

\section{Gaps and next steps}

Many questions remain unanswered about how to best detect C. auris and limit its spread within and between Canadian health care facilities. Knowledge gaps regarding the optimal laboratory detection and identification of $C$. auris should be addressed by bolstering existing biochemical and MALDI-TOF identification databases and by developing simple, rapid and sensitive laboratory screening protocols. Uncertainties that affect infection prevention and control practices for $C$. auris include the duration that patients remain colonized (and thus how long patients should be isolated after first detection) and optimal screening strategies. For example, should screening be reserved for patients with documented contact with a known case or used for all patients who have travelled to or received health care in areas where C. auris is prevalent? Because the geographic distribution of $C$. auris will change over time, and in light of incomplete surveillance data from many regions, identifying patients at high risk for colonization can be challenging for front-line health care workers.

To better understand the epidemiology of C. auris in Canada, the Canadian Nosocomial Infection Surveillance Program is conducting national surveillance for infections in representative hospitals across the country. (Garcia Jeldes F, Mitchell R, Bharat A, McGeer A for the CNISP C. auris Interest Group. Preparedness for Candida auris in Canadian Nosocomial Infection Surveillance Program [CNISP] Hospitals, 2018. IDWeek 2018. October 3-7, 2018. San Francisco, California). In addition, a point prevalence study is planned to identify the prevalence of both colonization and infection in Canadian tertiary care hospitals (Dr. Allison McGeer, September 2018, personal communication). The surveillance and point prevalence data will provide evidence needed to guide the development of infection prevention and control policies surrounding this emerging pathogen.

\section{Conflict of Interest}

None.

\section{References}

1. Schwartz IS, Hammond GW. First reported case of multidrug-resistant Candida auris in Canada. Can Commun Dis Rep 2017 Jul;43(7/8):150-3. DOl PubMed

2. Clancy CJ, Nguyen MH. Emergence of Candida auris: an international call to arms. Clin Infect Dis 2017 Jan;64(2):141-3. DOI PubMed

3. Lamoth F, Kontoyiannis DP. The Candida auris alert: facts and perspectives. J Infect Dis 2018 Jan;217(4):516-20. DOI PubMed

4. Centers for Disease Control and Prevention. Tracking Candida auris. Atlanta (GA): CDC; 2018. https://www.cdc.gov/fungal/ diseases/candidiasis/tracking-c-auris.html

5. Lockhart SR, Etienne KA, Vallabhaneni S, Faroogi J, Chowdhary A, Govender NP, Colombo AL, Calvo B, Cuomo CA, Desjardins CA, Berkow EL, Castanheira M, Magobo RE, Jabeen K, Asghar RJ, Meis JF, Jackson B, Chiller T, Litvintseva AP. Simultaneous emergence of multidrug-resistant Candida auris on 3 continents confirmed by whole-genome sequencing and epidemiological analyses. Clin Infect Dis 2017 Jan;64(2):134-40. DOI PubMed

6. van Schalkwyk E, Shuping L, Ismail H, Thomas J, Govender NP. Independent risk factors associated with Candida auris candidaemia in South Africa - an analysis of national surveillance data, 2016-2017. South Afr J Infect Dis 2017;Supp: FIDSSA Oral Presentation Abstracts. https://www.fidssa.co.za/content/ images/fidssa_abstracts.pdf

7. Chowdhary A, Anil Kumar V, Sharma C, Prakash A, Agarwal K, Babu R, Dinesh KR, Karim S, Singh SK, Hagen F, Meis JF. Multidrug-resistant endemic clonal strain of Candida auris in 
India. Eur J Clin Microbiol Infect Dis 2014 Jun;33(6):919-26. DOI PubMed

8. Mathur P, Hasan F, Singh PK, Malhotra R, Walia K, Chowdhary A. Five-year profile of candidaemia at an Indian trauma centre: high rates of Candida auris blood stream infections. Mycoses 2018 May;61(9):674-80. DOI PubMed

9. Kohlenberg A, Struelens MJ, Monnet DL, Plachouras D; The Candida Auris Survey Collaborative Group. Candida auris: epidemiological situation, laboratory capacity and preparedness in European Union and European Economic Area countries, 2013 to 2017. Euro Surveill 2018 Mar;23(13): DOI PubMed

10. ProMED. Candida auris - Canada: (BC) ex India, coinfect. carbapenemase-pos. bacteria, VRE 20170923.5335411. Brookline (MA): International Society for Infectious Diseases; 2017 Sep 23. http://www. promedmail.org/direct. php?id=20170923.5335411

11. Bharat A, Tyler AD, Knox NC, Mabon P, Schwartz IS, Hammond GW, van Domselaar G, Antonation KS, Mulvey MR. Poster: Genomic characterization of the first multidrug-resistant Candida auris isolated in Canada. In: 14th ASM Conference on Candida and Candidiasis April 15-19, 2018, Providence (RI); 2018. https://www.asm.org/images/ASM-Conferences/Candida/ Poster\%20Session\%20B.pdf

12. Chowdhary A, Sharma C, Meis JF. Candida auris: A rapidly emerging cause of hospital-acquired multidrug-resistant fungal infections globally. PLoS Pathog 2017 May;13(5):e1006290. DOI PubMed

13. Ruiz-Gaitán A, Moret AM, Tasias-Pitarch M, Aleixandre-López Al, Martínez-Morel H, Calabuig E, Salavert-Lletí M, Ramírez P, López-Hontangas JL, Hagen F, Meis JF, Mollar-Maseres J, Pemán J. An outbreak due to Candida auris with prolonged colonisation and candidaemia in a tertiary care European hospital. Mycoses 2018 Jul;61(7):498-505. DOl PubMed

14. Adams E, Quinn M, Tsay S, Poirot E, Chaturvedi S, Southwick K, Greenko J, Fernandez R, Kallen A, Vallabhaneni S, Haley V, Hutton B, Blog D, Lutterloh E, Zucker H, Candida auris Investigation Workgroup. Candida auris in Healthcare Facilities, New York, USA, 2013-2017. Emerg Infect Dis 2018 Oct;24(10):1816-24. DOI PubMed

15. Choi HI, An J, Hwang JJ, Moon SY, Son JS. Otomastoiditis caused by Candida auris: case report and literature review. Mycoses 2017 Aug;60(8):488-92. DOI PubMed

16. Kim MN, Shin JH, Sung H, Lee K, Kim EC, Ryoo N, Lee JS, Jung SI, Park KH, Kee SJ, Kim SH, Shin MG, Suh SP, Ryang DW. Candida haemulonii and closely related species at 5 university hospitals in Korea: identification, antifungal susceptibility, and clinical features. Clin Infect Dis 2009 Mar;48(6):e57-61. DOI PubMed

17. Satoh K, Makimura K, Hasumi Y, Nishiyama Y, Uchida K, Yamaguchi H. Candida auris sp. nov., a novel ascomycetous yeast isolated from the external ear canal of an inpatient in a Japanese hospital. Microbiol Immunol 2009 Jan;53(1):41-4. DOI PubMed

18. Jeffery-Smith A, Taori SK, Schelenz S, Jeffery K, Johnson EM, Borman A. Candida auris Incident Management Team, Manuel $\mathrm{R}$, Brown CS. Candida auris: a review of the literature. Clin Microbiol Rev 2017 Nov;31(1):e00029-17. DOl PubMed

19. Rudramurthy SM, Chakrabarti A, Paul RA, Sood P, Kaur H, Capoor MR, Kindo AJ, Marak RSK, Arora A, Sardana R, Das S, Chhina D, Patel A, Xess I, Tarai B, Singh P, Ghosh A. Candida auris candidaemia in Indian ICUs: analysis of risk factors. $J$ Antimicrob Chemother 2017 Jun;72(6):1794-801. DOI PubMed

20. Morales-López SE, Parra-Giraldo CM, Ceballos-Garzón A, Martínez HP, Rodríguez GJ, Álvarez-Moreno CA, Rodríguez JY. Invasive infections with multidrug-resistant yeast Candida auris, Colombia. Emerg Infect Dis 2017 Jan;23(1):162-4.

DOI PubMed

21. Lockhart SR, Berkow EL, Chow N, Welsh RM. Candida auris for the clinical microbiology laboratory: not your grandfather's Candida species. Clin Microbiol Newsl 2017 Jul;39(13):99-103. DOI PubMed

22. Pappas PG, Lionakis MS, Arendrup MC, Ostrosky-Zeichner L, Kullberg BJ. Invasive candidiasis. Nat Rev Dis Primers 2018 May;4:18026. DOI PubMed

23. Pfaller MA. Nosocomial candidiasis: emerging species, reservoirs, and modes of transmission. Clin Infect Dis 1996 May;22 Suppl 2:S89-94. DOI PubMed

24. Schelenz S, Hagen F, Rhodes JL, Abdolrasouli A, Chowdhary A, Hall A, Ryan L, Shackleton J, Trimlett R, Meis JF, Armstrong-James D, Fisher MC. First hospital outbreak of the globally emerging Candida auris in a European hospital. Antimicrob Resist Infect Control 2016 Oct;5:35. DOI PubMed

25. Escandón P, Chow NA, Caceres DH, Gade L, Berkow EL, Armstrong P, Rivera S, Misas E, Duarte C, Moulton-Meissner H, Welsh RM, Parra C, Pescador LA, Villalobos N, Salcedo S, Berrio I, Varón C, Espinosa-Bode A, Lockhart SR, Jackson BR, Litvintseva AP, Beltran M, Chiller TM. Molecular epidemiology of Candida auris in Colombia reveals a highly-related, country-wide colonization with regional patterns in Amphotericin $B$ resistance. Clin Infect Dis 2018 May.DOI PubMed

26. Kathuria S, Singh PK, Sharma C, Prakash A, Masih A, Kumar A, Meis JF, Chowdhary A. Multidrug-resistant Candida auris misidentified as Candida haemulonii: characterization by matrix-assisted laser desorption ionization-time of flight mass spectrometry and DNA sequencing and its antifungal susceptibility profile variability by Vitek 2 , CLSI broth microdilution, and Etest method. J Clin Microbiol 2015 Jun;53(6):1823-30. DOI PubMed

27. Mizusawa $M$, Miller $H$, Green $R$, Lee $R$, Durante $M$, Perkins $R$, Hewitt C, Simner PJ, Carroll KC, Hayden RT, Zhang SX. Can multidrug-resistant Candida auris be reliably identified in clinical microbiology laboratories? J Clin Microbiol 2017 Feb;55(2):63840. DOI PubMed

28. Chowdhary A, Prakash A, Sharma C, Kordalewska M, Kumar A, Sarma S, Tarai B, Singh A, Upadhyaya G, Upadhyay S, Yadav P, Singh PK, Khillan V, Sachdeva N, Perlin DS, Meis JF. A multicentre study of antifungal susceptibility patterns among 350 Candida auris isolates (2009-17) in India: role of the ERG11 and FKS1 genes in azole and echinocandin resistance. J Antimicrob Chemother 2018 Apr;73(4):891-9. DOI PubMed

29. Kordalewska M, Lee A, Park S, Berrio I, Chowdhary A, Zhao $Y$, Perlin DS. Understanding echinocandin resistance in the emerging pathogen Candida auris. Antimicrob Agents Chemother 2018 May;62(6):e00238-18. DOI PubMed

30. Welsh RM, Bentz ML, Shams A, Houston H, Lyons A, Rose LJ, Litvintseva AP. Survival, persistence, and isolation of the emerging multidrug-resistant pathogenic yeast Candida auris on a plastic health care surface. J Clin Microbiol 2017 Oct;55(10):2996-3005. DOI PubMed 
31. Madder H, Moir I, Moroney R, Butcher L, Newnham R, Sunderland M, Clarke T, Foster D, Hoffman P, Moore G, Brown CS, Jeffery KJM. Multiuse patient monitoring equipment as a risk factor for acquisition of Candida auris. bioRxiv 2017:149054. DOI

32. Gordon M, Ruiz J, Villarreal E, Sáez Esteve I, Simó Martín C, Pérez Riera I, Gil LÁ, Castañeda Segura MJ, Ruiz A, Frasquet J, Peman Garcia J, Castellanos Á, Ramirez Galleymore P. First report of a textile environmental reservoir outbreak of Candida auris in a medical intensive care unit. In ECCMID April 22, 2018, Madrid (ES); 2018. http://www.eccmidlive.org/\#resources/firstreport-of-an-textile-environmental-reservoir-during-an-outbreakof-candida-auris-in-a-medical-intensive-care-unit

33. Kean R, Sherry L, Townsend E, McKloud E, Short B, Akinbobola A, Mackay WG, Williams C, Jones BL, Ramage G. Surface disinfection challenges for Candida auris: an in-vitro study. J Hosp Infect 2018 Apr;98(4):433-6.

DOl PubMed

34. Cadnum JL, Shaikh AA, Piedrahita CT, Sankar T, Jencson AL, Larkin EL, Ghannoum MA, Donskey CJ. Effectiveness of disinfectants against Candida auris and other Candida species. Infect Control Hosp Epidemiol 2017 Oct;38(10):1240-3. DOI PubMed
35. Cadnum JL, Shaikh AA, Piedrahita $C T$, Jencson $A L$, Larkin EL, Ghannoum MA, Ghannoum MA, Donskey CJ. Relative resistance of the emerging fungal pathogen Candida auris and other Candida species to killing by ultraviolet light. Infect Control Hosp Epidemiol 2018 Jan;39(1):94-6. DOI PubMed

36. Abdolrasouli A, Armstrong-James D, Ryan L, Schelenz S. In vitro efficacy of disinfectants utilised for skin decolonisation and environmental decontamination during a hospital outbreak with Candida auris. Mycoses 2017 Nov;60(11):758-63. DOI PubMed

37. Lockhart SR, Jackson BR, Vallabhaneni S, Ostrosky-Zeichner L, Pappas PG, Chiller T. Thinking beyond the common Candida species: need for species-level identification of Candida due to the emergence of multidrug-resistant Candida auris. J Clin Microbiol 2017 Dec;55(12):3324-7. DOI PubMed

38. Centers for Disease Control and Prevention. Recommendations for infection prevention and control for Candida auris. Atlanta (GA): CDC; 2018. https://www.cdc.gov/fungal/candida-auris/cauris-infection-control.html

39. Public Health England. Guidance for the laboratory investigation, management and infection prevention and control for cases of Candida auris. London (UK): Public Health England; 2016 Jun 27 [updated 2017 Aug 11]. Report No.: 2013122. https://www.gov.uk/government/publications/candida-aurislaboratory-investigation-management-and-infection-preventionand-control

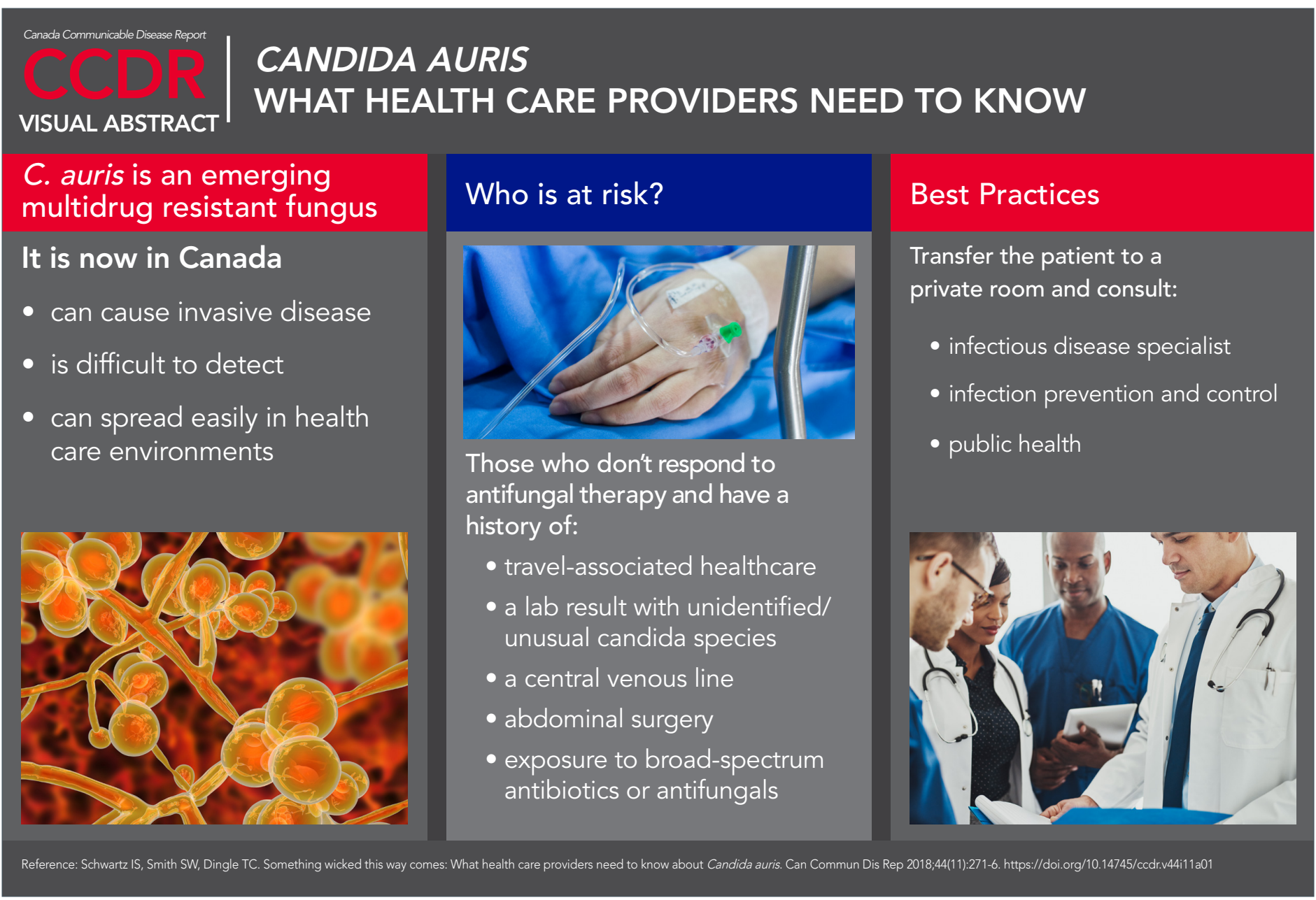

